\title{
Multivariate Analysis of Psychometric Variables Affecting Job Satisfaction Among School Teachers: A Case Study at Primary and Secondary Schools in Shashemene Town, Ethiopia
}

\author{
Sano Kedir Mohammed ${ }^{1 *} \quad$ Kemal Nure Kawo $^{2}$ \\ 1.Department of Statistics, Madda Walabu University, Robe, Ethiopia \\ 2. Department of Statistics, Madda Walabu University, Robe, Ethiopia
}

\begin{abstract}
This study has dealt with factors affecting the level of job satisfaction among school teachers at Shashemene town in 2010/11 academic year. Data were obtained from primary and secondary sources. A cross-sectional survey was conducted on a total of 405 teachers from different government and non-government schools using stratified random sampling technique. In the present study, the relationships between psychometric items (55-items) were examined by the combination of factor analysis and Bayesian logistic regression analysis. Firstly, factor analysis was used to group the items of the same characters as factors or explanatory variables of job satisfaction among teachers. Then, ten factors, having eigen-values greater than 1, were selected as independent variables and the factor scores coefficients were used in the Bayesian logistic regression analysis. It was found that eight unobserved variables had significant effects on job satisfaction.
\end{abstract}

Keywords: Psychometric variables, Factor analysis, job satisfaction, eigen-values, teachers.

DOI: $10.7176 / \mathrm{JEP} / 11-25-02$

Publication date:September $30^{\text {th }} 2020$

\section{Introduction}

The teachers' level of satisfaction has been identified as the critical factor in determining their performance and professional development. The subject has received increasing attention of researchers and scholars around the world since 1950s [1].

Many studies of job satisfaction have been carried out across the economy, education, etc. [2] have defined work satisfaction as an effective response or reaction to a wide range of conditions or aspects of one's work such as pay, supervision, working conditions and the work itself. Others have defined it as an effective orientation towards anticipated outcome [3] or an employee's effective reactions to a job based on comparing actual outcomes with desired outcomes [4]. It has been generally recognized as multifaceted construct that includes employees feeling about a variety of both intrinsic and extrinsic job elements [5]. Intrinsic determinants pertain to the nature of activities inherent to, a position or set of tasks such as intellectual stimulation or feeling of accomplishment. Extrinsic determinants focus on external factors such as relation with co-workers or job security. So, job satisfaction is a subjective variable which does not lead itself readily to quantification. It is experienced, when employees have fulfilled, whatever needs or considerations, they deem important in their work.

Most people in employment consciously experience a degree of satisfaction or dissatisfaction with their job. Moreover, they tend to be more satisfied with some aspects of their job than others. The relevance of job satisfaction is crucial to the long term growth of any work industry all over the world. This has to do with needs satisfaction which is essential in the lives of workers because it forms the fundamental reason for working [6]. People work because they expect returns or salary which will help to meet their needs in life.

The present study is an attempt to find out which facet or dimension affects the job satisfaction of primary and secondary school teachers significantly. The study has taken into account intrinsic and extrinsic factors to find out the level of job satisfaction and to see the effect of age, gender, marital status, educational level, occupational level and length of employment which are called demographic factors on the job satisfaction of academicians.

\subsection{Statement of the Problem}

Teachers' job satisfaction is a major and current issue of the international communities. Specially, in sub-Saharan countries, education is not up to the standard qualitatively and quantitatively, hence to improve these many factors has to be considered, but from these issues of teachers need to be studied. The questions that this study seeks to probe are as follows:

- What relationships (correlations) are there among the items of psychometric properties which shows feeling of teachers in many aspects?

- What are the most significant factors that influence overall job satisfaction of teachers with respect to psychometric variables?

The general objective of the study has been to determine or asses factors affecting overall job satisfaction among teachers at Shashemene town. 


\section{Data and Methodology}

The study was conducted in Shashemene town, a rapidly growing town in Oromia region of Ethiopia. Shashemene is centrally located, which is $250 \mathrm{~km}$ far from the capital city of Ethiopia, i.e. Addis Ababa. Geographically, it lies between Latitude of 7, $2000\left(712^{\prime} 0.000^{\prime \prime} \mathrm{N}\right)$ and Longitude of 38, $6000\left(3836^{\prime} 0.000^{\prime \prime} \mathrm{E}\right)$. The altitude of this town ranges from 1500metres to 2300meters above sea level. According to CSA (2007) report, the estimated population size of the town was 102,062, of which 51,477 were males and 50,585 were females. Educational institutes in the town, include one governmental TVET college, two non-governmental university college and four private colleges, three governmental high schools and two governmental preparatory schools.

In Shashemene town, there were 48 primary schools of which 10 were governmental and 38 were nongovernmental schools, having 278 and 501 teachers, respectively. There were also 10 high schools of which seven were non-governmental and three were governmental and there were six preparatory schools of which four were non-governmental and two were governmental. The total numbers of teachers employed in preparatory schools and high schools were 69 and 254, respectively [7].

The target populations for the study have been teachers employed in primary and secondary schools of governmental and non-governmental during 2010/11 at Shashemene town. These teachers were full timer paying tax from their salary. A cross- sectional survey design with stratified random sampling technique was used in this study.

\subsection{Multivariate Analysis}

Multivariate statistical methods have grown increasingly popular over the past twenty-five years. The continued explosion of multivariate statistical procedures can no doubt be attributable to the belief that models of nature and human behavior, must often account for multiple, inter-related variables that are conceptualized simultaneously or over time [8].

\subsubsection{Principal Component Analysis (PCA)}

According to [8], principal components are defined as linear combinations of random variables when seen analytically. Geometrically, these linear combinations represent the selection of a new coordinate system obtained by rotating the original coordinate system in such a way that the new axes represent directions with maximum variability and provide simpler description of covariance. The general objectives of principal component analysis (PCA) are the reduction of a large number of variables whose inter relationships are complex to a much smaller set of new variables whose interrelationships are simple, but which contain most of the variation in the original variables and ease of interpretation. PCA is a mathematical technique which does not require the user to specify an underlined statistical model to explain the error structure. In particular no assumption is made about the probability distribution of the original variables. PCA is done either using the theoretical covariance matrix $\Sigma$, or theoretical correlation matrix $\rho$ of $\mathrm{X}$, where $\mathrm{X}$ is a random vector with $\mathrm{p}$ dimensions. Usually the covariance matrix $(\Sigma)$ is used to analyze variables with the same unit of measurement. Since the correlation matrix is the covariance of a standardized variable, the correlation matrix $(\boldsymbol{\rho})$ has been used to analyze the variables with different unit of measurement.

As the unit of measurements of the variables, in this study is the same, it is possible to use either covariance or correlation matrix. The PCA was based on the correlation matrix $\rho$ of X. Algebraically; principal components (PCs) are those uncorrelated linear combinations $Y_{1}, Y_{2}, \ldots, Y_{p}$ whose variances are as large as possible. Geometrically; these linear combinations represent the selection of a new coordinate system obtained by rotating the original coordinate axes $X_{1}, X_{2}, \ldots, X_{p}$.

Let the covariance matrix associated with the random vector $X=\left(X_{1}, X_{2}, \ldots, X_{p}\right)^{T}$ has the eigenvalueeigenvector pairs $\left(\lambda_{1}, e_{1}\right),\left(\lambda_{2}, e_{2}\right), \ldots,\left(\lambda_{\mathrm{p}}, e_{p}\right)$ where $\lambda_{1} \geq \lambda_{2} \geq \ldots \geq \lambda_{\mathrm{p}}$, then the $\mathrm{i}^{\text {th }}$ principal component is given by

$$
Y_{i}=e^{T} X=e_{i 1} X+e_{i 2} X+\ldots .+e_{i p} X, i=1,2, \ldots, p
$$

With this choices

$$
\begin{aligned}
& \operatorname{Var}\left(X_{i}\right)=e^{T} \sum e=\lambda_{i}, i=1,2, \ldots, p \\
& \operatorname{Cov}\left(Y_{i}, Y_{k}\right)=e_{i}^{T} \sum e_{k}^{T}=0, i \neq k
\end{aligned}
$$

The PCA provides a highly parsimonious summary that might be useful in further analysis. So it is necessary to determine the number of components that are needed to provide an adequate summary of a given set of [8].

\section{The Number of Principal Components}

As a rule of thumb, only those components are retained whose variance $\lambda$ are greater than unity, or equivalently only those components are retained, which individually explain at least a proportion $1 / p$ of the total variance. 
Another useful visual aid determining an appropriate number of PCs is the scree plot. It is a plot of $\lambda_{\mathbf{i}}$ versus $i$, with eigenvalues ordered from largest to smallest (the magnitude of eigenvalues versus its number). Then, to determine the appropriate number of components, one looks for elbows (bends) in the scree plot. The number of components is taken to be the point at which the remaining eigenvalues are relatively small and all are about the same size.

\subsubsection{Factor Analysis}

Factor analysis is a statistical technique by which one describes (if possible) the covariance relationship among many variables in terms of few underlying unobservable random quantities called factors. The underlying idea in factor analysis is grouping variables that are highly correlated together to form a single underlying factor that is responsible for the observed correlation.

\section{The Orthogonal Factor Model}

Let the observed random vector $\mathrm{X}_{\text {with p component has mean }}{ }^{\mu}$ and covariance matrix $\Sigma$. The factor model postulates that $\mathrm{X}$ is linearly dependent upon a few unobservable random variables $F_{1}, F_{2}, \ldots, F_{m}$ and p additional source of variation $\varepsilon_{1}, \varepsilon_{2}, \ldots, \varepsilon_{p}$ called specific errors where $\mathrm{m}<\mathrm{p}$. The factor model in matrix notation is

$$
\mathrm{X}-\mu=\underset{(p \times m)}{L} F+\boldsymbol{\varepsilon}
$$

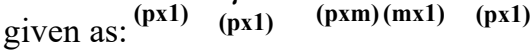

Where $L=\left({ }^{\ell_{i j}}\right)$ is matrix of loadings ${ }^{\ell_{i j}}$ is loading of the $\mathrm{i}^{\text {th }}$ variable on $\mathrm{j}^{\text {th }}$ factor.

$$
L_{(p x m)}=\left[\begin{array}{ccc}
\ell_{11}, & \ell_{12}, \ldots, & \ell_{1 m} \\
\ell_{21}, & \ell_{22}, \ldots, & \ell_{2 m} \\
\cdot & . & \cdot \\
\cdot & . & \cdot \\
\ell_{p 1} & \ldots \ldots . . . . & \ell_{p m}
\end{array}\right], F^{\prime}=\left[F_{1}, F_{2}, \ldots, F_{m}\right] \text { and } \boldsymbol{\varepsilon}^{\prime}=\left[\varepsilon_{1}, \varepsilon_{2}, \ldots, \varepsilon_{p}\right] \text {. }
$$

\section{Assumptions of Factor Model}

The assumptions of orthogonal factor model (equation 3.4) are

1. $\mathrm{E}(F)=\mathbf{0}$

2. $\operatorname{cov}(F)=I_{m}=\mathrm{E}\left(F F^{\prime}\right)$

3. $\mathrm{E}(\boldsymbol{\varepsilon})=\mathbf{0}$

4. $\operatorname{cov}(\varepsilon)=\mathrm{E}\left(\boldsymbol{\varepsilon} \boldsymbol{\varepsilon}^{\prime}\right)=\Psi_{p x p}$ where $\Psi_{\text {is diagonal matrix }}$

5. $\operatorname{cov}(\boldsymbol{\varepsilon}, F)=\mathrm{E}\left(\boldsymbol{\varepsilon} F^{\prime}\right)=\mathbf{0}_{p x m}$

\section{Covariance Structure for Orthogonal Factor Model}

The orthogonal factor model implies the covariance matrix $\Sigma$ of $\mathrm{X}$ has the form

1. $\Sigma=L L^{\prime}+\Psi$

2. $\operatorname{var}\left(\mathrm{X}_{i}\right)=\ell_{i 1}^{2}+\ell_{i 2}^{2}+\ldots+\ell_{i m}^{2}+\Psi_{i}, \mathrm{i}=1,2, \ldots, \mathrm{p}$ and $\Psi_{i}$ is $\mathrm{i}^{\text {th }}$ specific factor.

3. $\mathrm{E}\left(\mathrm{X}_{i}, X_{k}\right)=\ell_{i 1} \ell_{k 1}+\ell_{i 2} \ell_{k 2}+\ldots+\ell_{i m} \ell_{k m}$

4. $\operatorname{cov}\left(\mathrm{X}_{i}, F_{j}\right)=\ell_{i j}, \mathrm{i}=1,2, \ldots, \mathrm{p}$ and $\mathrm{j}=1,2, \ldots, \mathrm{m}$

5. $\operatorname{cov}(\mathrm{X}, F)=L$

The portion of variance of $\mathrm{i}^{\text {th }}$ variable contributed by the $\mathrm{m}$ common factors is called the $\mathrm{i}^{\text {th }}$ communality and that portion of variance of $\mathrm{i}^{\text {th }}$ variable $\mathrm{X}_{i}$ due to the specific factor is called specific error.

The $\mathrm{i}^{\text {th }}$ Communality is defined by

$$
h_{i}^{2}=\ell_{i 1}^{2}+l_{i 2}^{2}+\ldots+l_{i m}^{2}, \mathrm{i}=1,2, \ldots, \mathrm{p}
$$

The factor model assumes that the $\frac{p+\frac{p(p-1)}{2}}{2}$ variances and co-variances of $X$ can be reproduced from the 
pm factor loadings $l_{\mathrm{ij}}$ and p specific variances $\Psi_{i}$. Thus, the factor model explains the covariance matrix $\Sigma_{\text {with }}$ fewer (i.e. $p+$ pm) parameters.

\section{Estimation of Factor Loading}

The orthogonal factor model is essential when the covariance matrix $\mathrm{X}$ deviates significantly from diagonal matrix. The initial problem is estimation of the factor loadings $l_{\mathrm{ij}}$ and the specific variances $\Psi_{\mathbf{i}}$. The two popular methods of estimating are principal component method and maximum likelihood method. In this study, only the principal component method was used.

\section{The Principal Component Method}

The spectral decomposition of the covariance matrix provides us one factoring of $\Sigma$. Let $\Sigma$ have eigenvalueeigenvector pairs $\left(\lambda_{i}, e_{\mathbf{i}}\right)_{\text {with }} \lambda_{1} \geq \lambda_{2} \geq \ldots . . \lambda_{p} \geq 0$ then $\Sigma$ can be written as:

$$
\Sigma=\lambda_{1} \mathbf{e}_{1} \mathbf{e}_{1}^{\prime}+\lambda_{2} \mathbf{e}_{2} \mathbf{e}_{2}^{\prime}+\ldots+\lambda_{p} \mathbf{e}_{\mathbf{p}} \mathbf{e}_{\mathbf{p}}^{\prime}
$$

This first prescribed covariance structure for the factor analysis model have as many factors as variables and specific variances $\Psi_{i=0}$ for all i the loading matrix is $L=\left\lfloor\sqrt{\lambda_{1}} \mathbf{e}_{1}, \sqrt{\lambda_{2}} \mathbf{e}_{2}, \cdots, \sqrt{\lambda_{p}} \mathbf{e}_{p}\right\rfloor$ that is $\Sigma=L L^{\prime}$ ( equation 3.6) is exact form and it has as many common factors as there are variables, hence it does not result in data reduction. One prefers models that explain the covariance structure in terms of few common factors. One approach is to neglect the last $\mathrm{p}-\mathrm{m}$ eigenvalues that are small. Then one has the approximation: $\sum \approx \lambda_{1} e_{1} e_{1}^{T}+\lambda_{2} e_{2} e_{2}^{T}+\ldots+\lambda_{m} e_{m} e_{m}^{T}=L L^{\prime}$.

\section{The Contribution to the Total Sample Variances}

In applying the principal component to perform factor analysis, one uses the sample covariance matrix $S$ or the sample correlation matrix $R$.

Trace of the sample covariance matrix $=\operatorname{tr}\left(S_{)}\right) S_{11}+S_{22}+\ldots+S_{P P}$ and the trace of sample correlation matrix $\operatorname{tr}(R)=\hat{\lambda}_{1}+\hat{\lambda}_{2}+\ldots+\hat{\lambda}_{p}=p$, where $\hat{\lambda}_{1}, \hat{\lambda}_{2}, \ldots, \hat{\lambda}_{p}$ are eigen-values of the sample covariance matrix $\mathbf{S}$ Thus,

$$
\left(\begin{array}{l}
\text { proportion of total } \\
\text { sample variance } \\
\text { due to } \mathrm{j} \text { th factor }
\end{array}\right)=\left\{\begin{array}{l}
\frac{\hat{\lambda}_{j}}{\operatorname{tr}(S)} \text { for a factor analysis of sample covariance. } \\
\frac{\hat{\lambda}_{j}}{P} \text { for a factor analysis of correlation. }
\end{array}\right.
$$

The number of common factors retained in the model is increased until a suitable proportion of the total sample variance has been explained. As a rule of thumb (or convention), the number of common factors $\mathrm{m}$ is set to be equal to the number of eigenvalues of the sample correlation matrix $R$ greater than one if the sample correlation matrix is factored, or the number of common factors $m$ is set to be equal to the number of positive eigenvalues of $\mathbf{S}$ if the sample covariance matrix is factored.

\section{Factor Rotation}

Factor rotation is an orthogonal transformation of the factor loading since the original factor loadings may not be readily interpretable. The rationale behind is very much kin to sharpening the focus of a microscope in order to see the detail more clearly.

If $\hat{\mathbf{L}}$ is the pxm matrix of estimated factor loadings, then $\hat{L}^{*}=\hat{L} T$, where $T T^{\prime}=T^{\prime} T=I$ is pxm matrix of rotated loadings. The estimated covariance (or correlation) matrix remains unchanged since $\hat{\mathbf{L}} \hat{\mathbf{L}}^{\prime}+\hat{\boldsymbol{\Psi}}=\hat{\mathbf{L}} \mathbf{T} \mathbf{T}^{\prime} \hat{\mathbf{L}}^{\prime}+\hat{\boldsymbol{\Psi}}=\hat{\mathbf{L}}^{*} \hat{\mathbf{L}}^{*}+\hat{\mathbf{\Psi}}$. Moreover, specific variances, communalities and residual matrices remain unchanged. Since the original loadings (initial loadings) may not have an easy interpretation, it is usually a common practice to rotate them until a simple structure is achieved. The rotation should be such that each variable loads high on a single factor and has small to moderate loading on the remaining factor.

The most widely used factor rotation is Kaiser's Varimax rotation. If one defines

$$
\tilde{\ell}_{i j}^{*}=\frac{\hat{\ell}_{i j}^{*}}{\hat{h}_{i}} \text { to be the final rotated }
$$


coefficients scaled by the square root of the communalities, then the varimax procedure selects the orthogonal transformation $\mathrm{T}$ such that:

$$
V=\frac{1}{p} \sum_{j=1}^{m}\left(\sum_{i=1}^{p}\left(\widetilde{\ell}_{i j}^{*}\right)^{4}-\frac{\left(\sum_{i=1}^{p} \widetilde{\ell}_{i j}^{*}\right)^{2}}{p}\right)
$$

is as large as possible.

\section{Results and Discussion}

It can be seen from Table 1, 48.1\% governmental school teachers, of which $54.4 \%$ were of elementary and $45.6 \%$ were of secondary school teachers, whereas $51.9 \%$ were non-governmental school teachers, of which $80.5 \%$ were from elementary schools and $19.5 \%$ were from high schools.

Table 1: Cross Tabulation of School Type with School Level.

\begin{tabular}{|l|r|r|r|r|r|r|}
\hline \multirow{2}{*}{ Type school Vs Level of school } & \multicolumn{2}{|c|}{ Elementary } & \multicolumn{2}{|c|}{ Secondary } & \multicolumn{2}{c|}{ Total } \\
\cline { 2 - 7 } & $\mathrm{N}$ & \multicolumn{1}{c|}{$\%$} & $\mathrm{~N}$ & \multicolumn{1}{c|}{ \% } & \multicolumn{1}{c|}{ N } \\
\hline Government & 106 & $54.4 \%$ & 89 & $45.6 \%$ & 195 & $48.1 \%$ \\
\hline Non-governmental & 169 & $80.5 \%$ & 41 & $19.5 \%$ & 210 & $51.9 \%$ \\
\hline Total & 275 & $67.9 \%$ & 130 & $32.1 \%$ & 405 & $100 \%$ \\
\hline
\end{tabular}

\subsection{Data Reduction}

Performing principal component analysis helps firstly to identify interdependence in the independent variables, secondly to derive few numbers of manageable and meaningful constructs with a minimum loss of information and thirdly to get reliable measure to those interdependent variables. There were 55-items of psychometric character to be analyzed in data reduction stage. Ten principal components were extracted from the 55 variables which were retained in data reduction. As a rule of thumb it is checked by the scree plots, in which the components were retained whose variance $\lambda$ were greater than unity. Forty two of the 55 variables were retained in data reduction as can be checked by the criterion in the factor analysis.

Prior to analyzing, the reliability of the data was checked with Cronbach's $\alpha$. Sampling adequacy were checked using Kaiser-Meyer-Olkin (KMO) and Bartlett's test of sphericity were observed to check the significance of the correlation matrix. To keep the reliability and high sampling adequacy, psychometric variables, with cumulative extraction greater than 0.55 , were retained in the analysis.

\subsection{Factor Analysis}

An exploratory factor analysis was carried out to examine the factor structure of the 55 -items scale. The principal component method with varimax rotation was conducted to assess the underlying structure for the 55-items of the psychometric properties so that the final factors were uncorrelated with each other. As a result, one can assume that the information explained by one factor is independent of the information in the other factors. Before factor analysis, the overall reliability of items was checked and Cronbach's alpha was 0.898 for all 55-items and it was 0.885 for the selected 42 -items, then the items were consistent. Using SPSS, the factor analysis program generates a number of tables depending on the options one chooses. Several assumptions were also tested from the tables of the output. The $2^{\text {nd }}$ part of the questionnaire containing 55-items, was used for exploratory factor analysis, and the determinant of correlation matrix, was below 0.00001 indicating multicollinearity problems. Looking at the correlation matrix and table of communalities, some of the items were eliminated and then 42 items were used for factor analysis. The selection was made by observing the variables which were correlated highly, rejecting the variables having communalities after extraction less than 0.55 . The Kaiser-Meyer-Olkin (KMO) measure of sampling adequacy was 0.867 which was greater than 0.70 , implying that enough items were predicted by each factor. The Bartlett's test of Sphericity showed that $\chi_{861}^{2}=9802.025$, p-value $<0.001$ and it was also significant indicating that the variables were correlated highly enough to provide a reasonable basis for factor analysis and indicated that the assumption was met. Moreover, the detailed results are given in appendix (Table B.1). Hence the data were suitable for factor analysis and multivariate analysis of variance.

In varimax rotation of factor analysis solution for the original 42 items, $70.12 \%$ of the total variance was explained by the first ten factors with factor loadings greater than 0.6 as shown in Table 1 .

The questions or items that loaded highly on factor one were related to motivation of the teacher which had eight items \{I read more to know the subject in detail, the subject I teach meets with my talent, I make enough preparation for all classes, the work of a teacher is very pleasant to me, I am very interested in clarifying the subject 
for students, I find my work mentally stimulating, the social status of the teaching profession is encouraging, teaching encourages me to be creative\}.

Factor two was renamed as to payment condition which included five items the income is same as my expectation, I am well paid in proportion to my ability, the salary is very poor with respect to that of other school, the payment condition is improper in our school, my salary adequately meets my needs $\}$.

Factor three was related to school administration containing five items the school administration praises good work, the School administration is fair and supportive, our school leader decides satisfying idea, my administrators support my decisions and actions, the behavior of our school leader is very good\}.

Factor four renamed as student behavior comprised of five items \{my students are hard-working and initiate me to do more, the students have positive behavior towards me, my students have a good communication with me, my students respect me as a teacher, my students have high motivation levels for learning\}.

Factor five was related to growth opportunity (promotion) which had four items the policy of promotion is satisfying in our school, the promotion policy makes me disappointed, the opportunity to advance professionally is good, the promotion in our school depends on ability and performance of a person\}.

Factor six was related to working conditions containing four items \{condition of the job gives me a sense of accomplishment, condition of work is challenging and tiresome to me, working condition in the school are comfortable, numbers of classes that I have to teach are overloaded\}.

Factor seven was related to co-workers condition which includes four items \{my colleagues are very helpful, my co-workers stimulate me to do better work, my co-workers are responsible and clever to do, I like the people with whom I work with\}.

Factor eight was related to school facility containing three items \{the recreational materials of the school are enough for recreation, there are enough books in my subject at the library, there are enough facilities of computer and other infra-structures\}.

Factor nine was related to personal life with two items \{I am very happy in my life, I feel secured in my life\}. Factor ten was related to curriculum condition with two items \{It is possible to finish the content of the textbook on time, the way that the curriculum designed is very good and comfortable for a teacher .

These factors account for $12.8 \%, 8.38 \%, 8.29 \%, 8.07 \%, 7.25 \%, 7.21 \%, 5.28 \%, 5.02 \%, 4.01 \%$ and $3.82 \%$ of the variation, respectively. The scree plot in appendix of (Figure A3.1) can be used when the sample size is large (around 300 cases and above) to extract the number of factors in the analysis.

The communalities of each variable before and after extraction, principal component analysis works on the initial assumption that all variance is common; therefore, before extraction, the communalities are all 1 . The communalities, in the column labeled extraction, reflect the common variance in the data structure. So for example, one can say that $78.8 \%$ of the variance associated with item one is common or shared variance and $76.3 \%$ of the variance associated with item two is common or shared Another way to look at these communalities is in terms of the proportion of variance explained by the underlying factors. After extraction, some of the factors were discarded and so some information was lost. The amount of variance in each variable that can be explained by the retained factors is represented by the communalities after extraction.

Table 2: Results of Factor Analysis Using Varimax Rotation of 42 Psychometric Variables for a Sample of 405 Teachers

\begin{tabular}{|l|c|c|c|c|c|c|c|c|c|c|}
\hline \multicolumn{2}{|c|}{ Accounted for 70.12\% } & \multicolumn{7}{|c|}{ Common Factors: Component } \\
\hline & F1 & F2 & F3 & F4 & F5 & F6 & F7 & F8 & F9 & F10 \\
\hline Eigen values & 5.4 & 3.5 & 3.5 & 3.4 & 3.1 & 3.0 & 2.2 & 2.1 & 1.7 & 1.6 \\
\hline I read more to know the subject in detail. & .86 & & & & & & & & & \\
\hline The subject I teaches meets with my talent. & .81 & & & & & & & & & \\
\hline I make enough preparation for classes. & .80 & & & & & & & & & \\
\hline The work of a teacher is very pleasant to me. & .76 & & & & & & & & & \\
\hline $\begin{array}{l}\text { I am very interested in clarifying the subject for } \\
\text { students. }\end{array}$ & .76 & & & & & & & & & \\
\hline I find my work mentally stimulating. & .74 & & & & & & & & & \\
\hline $\begin{array}{l}\text { The social status of the teaching profession is } \\
\text { encouraging. }\end{array}$ & .72 & & & & & & & & & \\
\hline Teaching encourages me to be creative. & .66 & & & & & & & & & \\
\hline The income is same as my expectation. & & .85 & & & & & & & & \\
\hline I am well paid in proportion to my ability. & & .85 & & & & & & & & \\
\hline $\begin{array}{l}\text { The salary is very poor with respect to that of other } \\
\text { school. }\end{array}$ & & -.83 & & & & & & & & \\
\hline The payment condition is improper in our school. & & -.82 & & & & & & & & \\
\hline My salary adequately meets my needs. & & .69 & & & & & & & & \\
\hline
\end{tabular}




\begin{tabular}{|c|c|c|c|c|c|c|c|c|c|c|}
\hline \multirow{2}{*}{ Accounted for $70.12 \%$} & \multicolumn{10}{|c|}{ Common Factors: Component } \\
\hline & F1 & $\mathrm{F} 2$ & F3 & F4 & F5 & F6 & F7 & F8 & F9 & F10 \\
\hline The school administration is fair and supportive. & & & .82 & & & & & & & \\
\hline The school administration praises good work. & & & .81 & & & & & & & \\
\hline Our school leader decides satisfying idea. & & & .78 & & & & & & & \\
\hline $\begin{array}{l}\text { My administrators support my decisions and } \\
\text { actions. }\end{array}$ & & & .77 & & & & & & & \\
\hline The behavior of our school leader is very good. & & & .67 & & & & & & & \\
\hline $\begin{array}{l}\text { My students are hard-working and initiate me to } \\
\text { do more. }\end{array}$ & & & & .76 & & & & & & \\
\hline The students have positive behavior towards me. & & & & .76 & & & & & & \\
\hline My students have a good communication with me. & & & & .75 & & & & & & \\
\hline My students respect me as a teacher. & & & & .70 & & & & & & \\
\hline $\begin{array}{l}\text { My students have high motivation levels for } \\
\text { learning. }\end{array}$ & & & & .69 & & & & & & \\
\hline $\begin{array}{l}\text { The policy of promotion is satisfying in our } \\
\text { school. }\end{array}$ & & & & & .90 & & & & & \\
\hline The promotion policy makes me disappointed. & & & & & -.83 & & & & & \\
\hline $\begin{array}{l}\text { The opportunity to advance professionally is } \\
\text { good. }\end{array}$ & & & & & .79 & & & & & \\
\hline $\begin{array}{l}\text { The promotion in our school depends on ability } \\
\text { and performance of a person. }\end{array}$ & & & & & .69 & & & & & \\
\hline $\begin{array}{l}\text { Condition of the job gives me a sense of } \\
\text { accomplishment. }\end{array}$ & & & & & & .87 & & & & \\
\hline $\begin{array}{l}\text { Condition of work is challenging and tiresome to } \\
\text { me. }\end{array}$ & & & & & & .86 & & & & \\
\hline Working conditions in the school are comfortable. & & & & & & .82 & & & & \\
\hline $\begin{array}{l}\text { Numbers of classes that I have to teach are } \\
\text { overloaded. }\end{array}$ & & & & & & .82 & & & & \\
\hline My colleagues are very helpful. & & & & & & & .82 & & & \\
\hline My co-workers stimulate me to do better work. & & & & & & & .75 & & & \\
\hline My co-workers are responsible and clever to do. & & & & & & & .61 & & & \\
\hline I like the people with whom I work with. & & & & & & & .54 & & & \\
\hline $\begin{array}{l}\text { The recreational materials of the school are } \\
\text { enough for recreation. }\end{array}$ & & & & & & & & .79 & & \\
\hline $\begin{array}{l}\text { There are enough books in my subject at the } \\
\text { library. }\end{array}$ & & & & & & & & .78 & & \\
\hline $\begin{array}{l}\text { There are enough facilities of computer and other } \\
\text { infra-structures. }\end{array}$ & & & & & & & & .69 & & \\
\hline I feel secured in my life. & & & & & & & & & .87 & \\
\hline I am very happy in my life. & & & & & & & & & .84 & \\
\hline $\begin{array}{l}\text { The way that the curriculum designed is very good } \\
\text { and comfortable for a teacher. }\end{array}$ & & & & & & & & & & .85 \\
\hline $\begin{array}{l}\text { It is possible to finish the content of the textbook } \\
\text { on time. }\end{array}$ & & & & & & & & & & .83 \\
\hline
\end{tabular}

The extraction method was principal component analysis and the rotation method was varimax with Kaiser Normalization to obtain orthogonal factors. Varimax rotation convergence was established after seven iterations.

From the results of bivariate analysis, the predictor variables considered in psychometric properties which were grouped in factor analysis like motivation, school administration, payment condition, growth opportunity, student behavior, working condition, co-workers (colleagues), school facility and curriculum condition. 
Table 3: Tests of Association between Satisfaction Levels with Factored Psychometric Instruments using Wald Statistic

\begin{tabular}{|l|r|r|r|}
\hline \multicolumn{1}{|c|}{ Variable/Factors } & Wald & df & P-value \\
\hline Motivation & 25.623 & 1 & .000 \\
\hline School administration & 14.660 & 1 & .000 \\
\hline Payment condition & 10.488 & 1 & .001 \\
\hline Working condition & 20.733 & 1 & .000 \\
\hline Co-workers condition & 10.268 & 1 & .001 \\
\hline Growth opportunity & 1.990 & 1 & .158 \\
\hline Student behavior & 6.164 & 1 & .013 \\
\hline School facility & 0.375 & 1 & .540 \\
\hline Curriculum condition & 6.772 & 1 & .009 \\
\hline Personal life & 6.592 & 1 & .010 \\
\hline
\end{tabular}

\subsection{Interpretation and discussions of the Results}

It can be seen from Table 3, that there was an association between psychometric factors and outcome variable except growth opportunity and school facility using the Wald statistic. Therefore, motivation, school administration, payment condition, working condition, student behavior, co-workers condition, curriculum condition and personal life were the candidate variables for the analysis.

\subsection{Conclusions}

The factor analyses conducted in this study indicated that ten factors instead of 42-items were sufficient to explain the total sample variance in job satisfaction. The psychometric properties were grouped in to ten factors. The predictor variables of job satisfaction of teachers were found to be motivation, working conditions, payment condition of teacher, student behavior, school administration, co-workers (colleagues) condition, personal life of teacher and curriculum condition.

\section{References}

[1] Masroor, A. (1999). A Comparative Study of Job Satisfaction among Teachers of Government and Private Secondary Schools in Karachi; Hamdard University, Pakistan.

[2] Tziner, A.E. and Verdi, Y. (1984). Work Satisfaction and Absenteeism Among Social.UNESCO. (2010). New Projections on the Global Demand for Teachers. UIS.

[3] Wanous, J.P. and Lawler, E.E. (1972). Measurement and Meaning of Job Satisfaction, Journal of Applied Psychology, 56(2), 95-104.

[4] Cranny, C.J., Smith, P.C. and Stone, E.F. (1992). Job Satisfaction: How People Feel about Their Jobs and How it Affects their Performance. Lexington Books, New York.

[5] Howard, J.L. and Frink, D.D. (1996). The Effects of Organizational Restructure on Employee satisfaction, Group and Organization Management, 21, 278-303.

[6] Ololube, N. (2005). Benchmarking the Motivational Competencies of Academically Qualified Teachers and Professionally Qualified Teachers in Nigerian Secondary Schools. The African Symposium, Vol. 5, No. 3. pp. 17-37.

[7] Education Bureau of Shashemee Twon, 2010 Jayanta, K., Mohan, D. and Tapa, S. (2006). An Introduction to Bayesian Analysis Theory and Methods.

[8] Johnson, A. (2007). Applied Multivariate Statistical Analysis (6 $6^{\text {th }}$ ed.), Pearson Prentice Hall, Trademark of Pearson Education, Upper Saddle River, New Jersey 07458. 